\title{
Viral infections
}

\author{
J. A. DUDGEON
}

From the Institute of Child Health, University of London

\section{Viral Infections}

During the past decade, 1966-1976, increasing interest has centred around the effect that infections acquired in pregnancy may have on fetal development and subsequent development after birth. The year 1966 was an important landmark in the study of viral infections acquired in pregnancy for the rubella vaccine trials (reported that year by Meyer et al, 1966), signalled the first attempt, by means of active immunization, to prevent the ill effects of a maternal infection upon the fetus. And now in 1976, serious consideration is being given to prevention of another, cytomegalovirus infection.

The recognition by Gregg (1941) of the association between maternal rubella and congenital rubella defects led inevitably to the belief that other viruses might have a similar action, but in the event only one other, cytomegalovirus (CMV), has been found to be a significant cause of congenital defects. Other viruses listed in table I do from time to time

\begin{tabular}{ll}
\hline Proven & Not Proven \\
\hline Rubella & Hepatitis A \\
Cytomegalovirus & Influenza \\
Herpes simplex & Mumps \\
Varicella-zoster & Coxsackie A or B \\
Variola-vaccinia & Echo viruses \\
Hepatitis B & \\
Poliomyelitis & \\
\hline
\end{tabular}

Table I Effect on the fetus of virus infections in pregnancy

infect the fetus and cause damage, but the incidence of fetal damage is small. Sever and White (1968) found that only $5 \cdot 2 \%$ of 30000 pregnancies were complicated by a virus infection and a further $2 \%$ if serological tests were carried out. However, this does not take into account the fact that subclinical or latent viral infections may have a more deleterious effect on the fetus than we, at present, realize (Catalano and Sever, 1971). As far as the others, such as hepatitis A, influenza, mumps and the enteroviruses, are concerned, there is no convincing evidence that maternal infection leads to congenital defects, although they may indirectly lead to an in- crease in fetal and infant mortality. Nevertheless this is an important area for investigation, principally because if a maternal infection can be identified as a cause of damage to the fetus or newborn, then the prospects of preventive measures being successful are better than in diseases of genetic or mixed genetic and environmental origin. For the purpose of this communication the term 'viral infections in pregnancy' will be taken to mean those infections acquired between conception and parturition and will include those congenital infections which, although acquired before birth, may not make themselves manifest until after birth.

If it is accepted that prevention is the ultimate objective in the study of virus infections in pregnancy, then it is necessary to obtain information on four related aspects: (1) the viral agents which are a significant cause of damage if infection occurs in pregnancy; (2) those factors which predispose to fetal damage; (3) the mode of infection and mechanisms of damage; and (4) details of the biological properties of the viruses responsible for fetal damage. In seeking to obtain this information it is helpful to study the way in which the evidence was obtained concerning the role of rubella virus as a cause of congenital defects. Gregg's original report (1941) recorded clinical observations of a repetitive pattern of defects, or clinical syndrome, associated retrospectively with an event in pregnancy. Epidemiological studies showed that the same clinical manifestations had been observed throughout Australia and many parts of the world. Twenty years later, with newly developed laboratory techniques available, it became possible to make a definitive and retrospective diagnosis of intrauterine rubella infection. The technique of virus isolation and tests for the persistence of rubella antibody, raised cord blood IgM levels and the presence of specific IgM antibody added much to our knowledge of congenital rubella. The evidence accumulated in this way has clearly established a cause and effect relationship between maternal rubella and certain congenital defects and the same applies to CMV infection. In attempting to establish a causal relationship between congenital defects and other virus infections, the 
1 Clinical

Each infection tends to produce a syndrome or repetitive pattern of clinical manifestations

2 Epidemiological

The same manifestations should be observed with the same agent following maternal illness in different countries

3 Virological

Persistence of the infective agent in fetal tissues and a chronic infective state after birth

4 Immunological

Persistence of antibody in the child after the normal decline of maternal antibody; presence of antibody in the IgM fraction; raised levels of total IgM

Table II Criteria for establishing a causal relationship between a maternal infection and congenital defects or fetal damage

criteria set out in table II should, as far as possible, be satisfied. It is not possible to satisfy them in all cases, but they serve as useful guidelines (Dudgeon, 1976).

\section{Congenital Rubella}

The original triad of symptoms-cataracts, heart disease and deafness-recognized by Gregg (1941) and Swan et al (1943) came to be known as the rubella syndrome. Following the rubella pandemics of 1963-1965 many additional clinical manifestations were observed as a direct consequence of intrauterine rubella. Details of these are set out in table III, but 'new' manifestations are still being reported (Cooper, 1975), and it seems clear that the final picture of the impact of rubella virus infection on the fetus will be vastly different from the original restricted concept of the rubella syndrome. The way in which these clinical manifestations of congenital rubella may present are outlined in the figure.

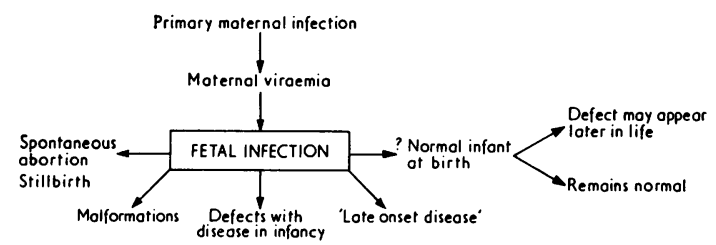

Fig. Consequences of intrauterine rubella infection. (After an illustration in Brit. med. Bull., 32, 1976, 77).

An increase in the fetal mortality rate has been noted by several investigators (Manson et al, 1960; Siegel et al, 1966), but it is not an important feature. Premature delivery is infrequent whereas intrauterine growth retardation of an infant of normal gestational age is common. Malformations of the heart, eyes and hearing organs are frequently present, together with other defects such as neonatal purpura, hepatosplenomegaly, jaundice and hepatitis. The mortality rate in early infancy is high (Cooper, 1968).

General

Intrauterine growth retardation; failure to thrive; retardation of postnatal growth

Eye Lesions

Cataracts $(80 \%$ bilateral); microphthalmos; pigmentary retinopathy; cloudy cornea; glaucoma; hypoplasia of iris, idiminished reaction to atropine

Cardiovascular Lesions

Persistent ductus arteriosus (PDA); PDA + pulmonary arterial lesions; pulmonary arterial lesions; (1) hypoplasia of artery, (2) supravalvular stenosis, (3) valvular stenosis, (4) peripheral branch stenosis; renal artery stenosis, ? cerebrovascular stenosis; aortic stenosis; ventricular septal defects; the tetralogy of Fallot; myocardial damage; neonatal myocarditis

Central Nervous System

Microcephaly; fullness of fontanelle; raised protein and cells in cerebrospinal fluid (CSF); mental retardation; cerebral palsy; lethargy, hypotonia leading to irritability; unreactive, hypotonic infant; late onset of irritability and hypotonia; late onset of convulsions and meningitis; progressive panencephalitis

Hearing and Speech

Sensorineural deafness; central auditory imperception; speech defects and deafness, with or without mental retardation; autism

Viscera

Hepatomegaly; hepatitis and jaundice; splenomegaly

Bone

Osteopathy

Blood

Thrombocytopenia; purpura; anaemia

Lungs

Interstitial pneumonitis

Skin

Chronic rubelliform rash

Miscellaneous

Persistent adenopathy; thymic hypoplasia; hypogammaglobulinaemia; recurrent or persistent diarrhoea; dermatoglyphic abnormalities; diabetes mellitus; ? growth hormone deficiency

Table III Clinical and pathological manifestations of congenital rubella ${ }^{1}$

'Taken from Dudgeon, J. A. (1976) 'Infective causes of human malformations'. In: Brit. med. Bull., 32, no. 1, pp. 77-83. table I (p. 78). 
Several features of congenital rubella, notably pneumonitis, rubelliform rashes, recurrent lung and gastrointestinal infections, may not develop until several months after birth; another well recognized feature of this so-called 'late-onset' disease is the type of sensorineural deafness which may not become evident until childhood. The same applies to a progressive form of encephalitis which can develop in the second decade of life (Townsend et al, 1975). A further important feature of congenital rubella is the fact that rubella in pregnancy, although frequently followed by fetal infection, does not always lead to fetal damage. It is now well established that the incidence of fetal infection in the first few weeks of pregnancy is very much higher than the incidence of congenital defects (Dudgeon, 1969). It can be seen from the figure that an infant apparently normal at birth may remain so or may develop signs of a defect after birth. The laboratory tests referred to in table II can provide useful information as to which of these infants have been infected as a result of exposure to maternal rubella and are, therefore, likely to be at greater risk. The risk to the fetus is determined by two factors: first, the immune status of the mother at the time of exposure to rubella, and secondly, the gestational age at which infection occurs. Primary maternal rubella in a susceptible woman without antibody at the time of exposure constitutes a risk to the fetus, whereas reinfection does not. Although there have been reports that reinfection has occasionally led to fetal damage (Weinstein et al, 1975), the evidence for this is slender, and the fact that there are no recorded and authentic cases of more than one case of congenital rubella in a family would appear to provide the strongest argument that reinfection is not a problem in the natural history of congenital rubella. The incidence of congenital rubella defects in liveborn infants summarized from several prospective studies between 1951 and 1964 is shown in table IV.

The detailed studies on congenital rubella patients over the past few years have also revealed important information on possible mechanisms of fetal damage. It seems likely that these are multifactorial rather than due to a single pathological process (Dudgeon, 1976). There is evidence of damage to placental and fetal blood vessels resulting in a sclerosing angiitis, of reduced mitotic activity and of cytolytic changes. Other defects can be attributed to persistence of virus and immunopathological mechanisms, but the vascular lesions may well be the most important of all.

Immunization against rubella with live attenuated vaccines, with the objective of preventing congenital rubella defects, was introduced in many countries in the early 1970s. Should these prove to be effective, the incidence of congenital rubella defects should decline during the next decade, and there is already some evidence from the United States (Cooper, 1975) that the incidence of rubella and congenital rubella is declining. The effectiveness of rubella vaccination programmes can only be determined by comprehensive and sustained surveillance programmes. The importance of these at the present time cannot be overemphasized.

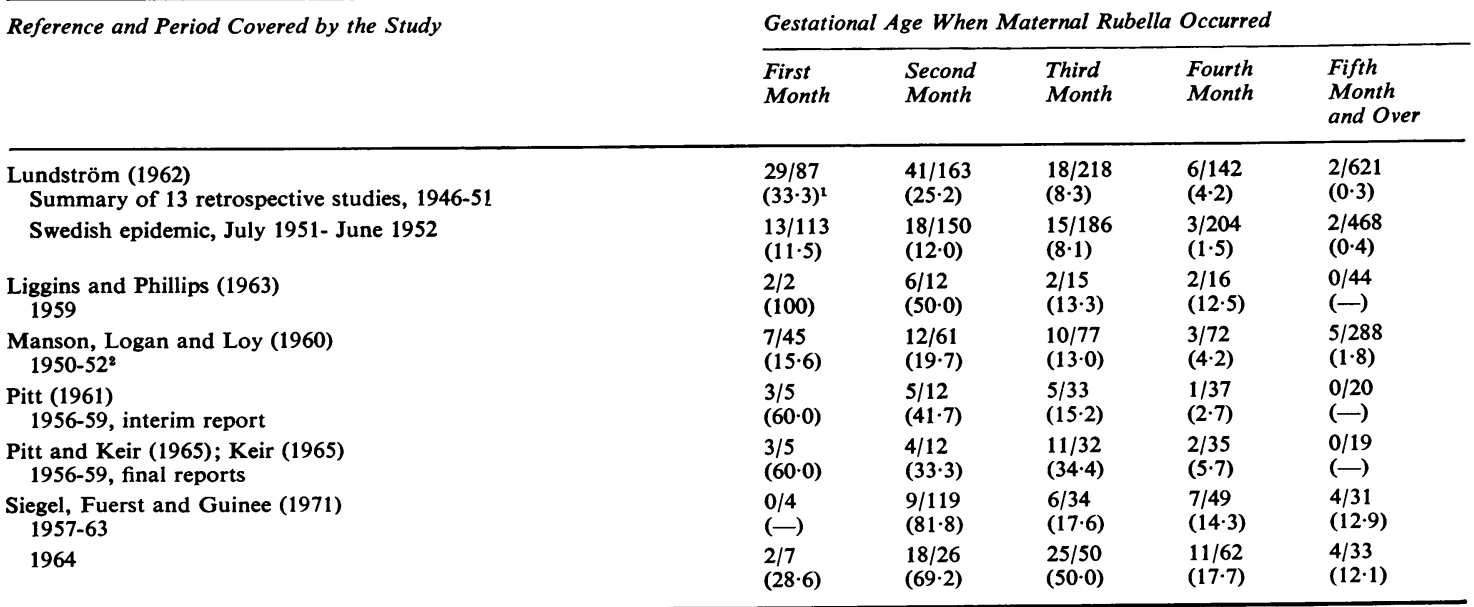

Table IV Incidence of congenital rubella defects in live-born infants

${ }^{2}$ Percentages given in parentheses.

In this study, one instance of a major defect, other than defects of the heart, eye and ear, and mental defects, was found as follows: erythroblastosis (at 0-4 weeks of pregnancy); oesophageal atresia, pyloric stenosis (at 5-8 weeks); duodenal atresia, pyloric stenosis (at 9-12 weeks); multiple gut defects (at 13-16 weeks); spina bifida, cleft palate, liver cyst, pyloric stenosis, imperforate anus (at 17 and more weeks).

Taken from Dudgeon, J. A. (1976) 'Infective causes of human malformations'. In: Brit. med. Bull., 32, no. 1, 77-83, table II (p. 79). 


\section{Congenital Cytomegalovirus Infection}

Cytomegalovirus is probably one of the most frequent viral infections of the human fetus and is a good example of how an inapparent, or latent, viral infection may have a deleterious effect upon the fetus. There are many points of similarity between congenital CMV and congenital rubella, both in respect of their clinical manifestations and natural history, but there are important differences which will be emphasized.

Cytomegalovirus is an extremely common virus infection of man but infection, unlike rubella, is nearly always asymptomatic. For this reason it is impossible, without serological tests, to determine the gestational age when the fetus becomes infected. Infection with CMV as determined by the acquisition of complement-fixing (CF) antibody appears to be acquired at two principal stages in life, whereas with rubella infection in most western countries takes place at a more regular rate. Stern (1975) has shown that in western countries CMV antibody develops fairly steadily from the age of 1 year to 15 years, by which stage 15 to $20 \%$ of individuals will have antibody. The next period of infection is between 15 and 30 years when about a third of the population will have acquired infection, so that primary infection is occurring with some degree of frequency during the main child-bearing period. In contrast, in crowded populations overseas, infection is acquired early in childhood leaving very few adults susceptible (Krech et al, 1971a). This pattern of events is probably related to the mode of spread of virus which requires close contact.

The consequences of intrauterine CMV infection follows the same pattern as shown in the figure for rubella, but again differences can be discerned. The relationship between inapparent maternal CMV and spontaneous abortion is uncertain. Various investigators have recovered CMV from aborted fetuses (Kriel et al, 1970) but these have not been confirmed by others (Boué and Loffredo, 1970; Marshall, 1972). The same wide spectrum of disease ranging from severe cytomegalic inclusion (CID) disease, transient purpura, thrombocytopaenia, with or without neonatal hepatitis, to an asymptomatic infection, is encountered as in congenital rubella. Details of these are shown in table $\mathrm{V}$ but the main difference is that the severe multisystem disease, CID, is uncommon, whereas asymptomatic infection is very common. A further difference is that in congenital CMV damage to the central nervous system is more frequent, and, except for the rare occurrence of microgyria, structural malformations as seen in congenital rubella are extremely rare. In both cases, however, there is a substantial risk that a congenitally infected infant will later develop signs of mental retardation, with or without microcephaly, or deafness. The size of that risk is not at present known, but is an important question to answer when considering the need for preventive measures.

The pathogenesis of CMV differs in several important ways from that of rubella. In postnatally acquired infections, virus can be recovered from the nasopharynx, saliva, urine, cervical secretions, semen and breast milk (Stern, 1975). Primary infection in children and adults is usually followed by transient excretion from the throat and urine, but infection may remain for longer periods in the uterine cervix. Cytomegalovirus behaves like other DNA viruses of the herpesvirus group in that virus is not completely eliminated following primary infection, but remains latent and, therefore, capable of reactivation. The two situations in which reactivation may occur are pregnancy and in patients on immunosuppressive therapy (Stern and Tucker, 1973). The virus excretion rate increases in seropositive women during pregnancy, being higher in the third trimester than in the first and second (Montgomery et al, 1972). Studies by Stagno et al (1975) indicate that early pregnancy has a suppressive effect on viral excretion. The overall recovery rate of virus from the cervix and urine of pregnant and non-pregnant females was similar, being $9.4 \%$ and $9.5 \%$ respectively. However, in the pregnant group the recovery rate in the first trimester was $1.6 \%$ compared with $11.3 \%$ in the third. Virus can be recovered from the same sources as before, so that

\begin{tabular}{lll}
\hline Generalized Cytomegalic Inclusion Disease (CID) & Localized Disease & Asymptomatic Infection \\
\hline Low birth weight & Purpura \\
Hepatosplenomegaly & Hepatitis \\
Hepatitis: jaundice & \\
Encephalitis & \\
Irritability: hypotonia & \\
Hydrocephalus & \\
Microcephaly & \\
Chorioretinitis & \\
Cerebral calcification & \\
\hline
\end{tabular}

Table V Consequences of congenital CMV infection 
at parturition the infant may become infected by cervical secretions or from virus-infected breast milk. Infants infected in this way may excrete virus for prolonged periods. There seems little doubt that primary infection associated with maternal viraemia is the main source of congenital infections with defects, but to what extent perinatal and early neonatal infections can lead to infection and damage to the infant brain is not known.

Hanshaw et al (1973) have estimated that between $0.4 \%$ and $1 \%$ of live-born infants are congenitally infected with CMV. Stern (1975) found that approximately $1-2 \%$ of pregnant women in London developed a primary $\mathrm{CMV}$ infection and that $50 \%$ of the newborns were infected and excreting virus at birth. In round numbers this means that as far as the UK is concerned, between 4000 and 10000 infected infants will be born each year and that of these, approximately $10 \%$ may be damaged. Although the rate of infection increases throughout pregnancy, the risk to the fetus does not. Monif et al (1972) found that mothers, who became infected in the second trimester, gave birth to infants with symptoms, whereas those infected during the third trimester had normal or uninfected infants. Serological tests carried out by Hanshaw et al (1973) indicate that children born to mothers who had CMV infection in pregnancy, but who had antibody at the time, which was not the result of a primary infection, were not infected. This strongly suggests that reactivation is not an important problem in the causation of defects; nevertheless there have been reports of congenital CMV in successive pregnancies (Embil et al, 1970; Krech et al, 1971b; Stagno et al, 1973), but it is not clear whether the second infected children are damaged. In one case reported by Stagno et al (1973) the second infected child has shown no evidence of physical or motor impairment at 9 months of age. Second infections could be related to reinfection with a different strain of virus, but as strains of CMV are so closely related this explanation seems improbable (Stagno et al, 1973).

Less is known about the pathology of congenital CMV than about congenital rubella, but necrotic and inflammatory changes appear to predominate in CMV. There is also evidence from the work of Hayes and Gibas (1971) that primary CMV infection may be halted at the level of the placenta with the result that the fetus is spared.

Congenital CMV presents a more important problem from the point of view of management and prevention than does rubella. More children are damaged by this virus; the damage is not amenable to corrective surgery as in the case of some of the defects caused by rubella virus. There is no simple way of telling when a primary CMV infection has occur- red in pregnancy. Finally, prevention by immunization, certainly with a live vaccine, presents a number of imponderable problems (Dudgeon, 1973). These are associated with latency of infection, and the possibility of oncogenicity with a DNA virus, and, although the risks may be small or even non-existent, there is no way known at present as how to answer them.

\section{Herpes Simplex Virus}

Herpes simplex virus (HSV) infections occur with even greater frequency than CMV infections, and again the majority are asymptomatic. Infection of the fetus and newborn can occur at two stages of pregnancy. The most frequent is late in pregnancy, or actually at birth, when the fetus may be infected as the result of an ascending cervical-amniotic infection from genital herpes of the mother or by being infected on passage through the birth canal. Neonatal infection is being recognized with increasing frequency due to a greater awareness of the frequency of genital herpes in women and improved methods of laboratory diagnosis. Nahmias et al (1975) have found that $88 \%$ of such infections are due to HSV type 2 strains; three-quarters of the isolates from 120 newborns were type 2 strains. However, no significant difference in the clinical manifestations have been observed between HSV-2 and HSV-1 strains. Both can cause disease ranging from severe disseminated infections involving the skin, viscera and brain to mild infection of the skin or oral mucosa, but subclinical infection in the newborn is very infrequent. Maternal genital herpes is also associated with increased abortion and premature delivery (Nahmias et al, 1971).

Transplacental infection may also occur leading to fetal infection earlier in pregnancy. Schaffer (1965) described a case with signs of microcephaly, periventricular intracranial calcifications, microphthalmia and cutaneous lesions from which HSV was isolated. The child was sick at birth and was probably infected early in fetal life. A case reported by South et al (1969), born at 33 weeks' gestation, had marked microcephaly, microophthalmia, intracranial calcification and retinal dysplasia. The mother had a history of genital herpes before and during the pregnancy. Montgomery et al (1973) described a further child with chorioretinitis and retardation, patent ductus arteriosus and short digits in whom skin lesions were present at birth and which persisted as scars. The mother had had a febrile illness at six weeks of gestation but no evidence of genital herpes. Herpes simplex virus -2 was recovered from the skin lesions at the age of 14 months. Congenital infection was presumed. Two additional cases with neuro- 
logical damage have been seen recently (Hanshaw, 1975).

Although so few cases have been reported, this may well be due to a lack of recognition of signs and symptoms which may be associated with intrauterine HSV infection and the absence of laboratory facilities to substantiate the diagnosis.

\section{Varicella-zoster Infections}

The effect of varicella-zoster (V-Z) infections on the fetus and newborn is similar in many respects to HSV infection. Maternal varicella acquired in the last 10 days of pregnancy can lead to infection, presenting at birth or early in the neonatal period (Gershon, 1975). The severity of the infection varies considerably; many infants escape infection altogether, others have a mild vesicular eruption, whilst a few develop a severe disseminated infection. The severity of the infant's illness appears to be related to the time of onset rather than to the severity of the maternal disease. In a series of 50 cases reviewed by Gershon (1975) it was found that where the mother's illness was contracted five days or more before delivery (and the onset of the baby's illness within four days of birth) all 27 infants survived; whereas if maternal varicella developed within four days of birth (and the baby's illness five to 10 days afterwards), seven out of 23 infants died (mortality rate $14 \%$ ). Overall, the mortality rate of neonatal varicella is from $14 \%$ to $31 \%$.

Varicella-zoster infection contracted early in pregnancy may rarely lead to congenital defects. Laforet and Lynch (1947) first drew attention to a possible relationship between varicella in pregnancy and a series of defects characterized by paralysis, muscular atrophy of a limb, cutaneous scars, rudimentary digits, convulsions and cortical atrophy. Since then seven other cases with essentially similar defects have been seen in different parts of the world (see reviews by Gershon 1975; Dudgeon, 1976). A summary of the main clinical findings is shown in table VI.

\begin{tabular}{ll}
\hline Defect & $\begin{array}{l}\text { No of Infants } \\
\text { Affected }\end{array}$ \\
\hline Low birth weight & $5 / 8$ \\
Cutaneous scars & $8 / 8$ \\
Hypoplasia of a limb & $6 / 8$ \\
Rudimentary digits & $4 / 8$ \\
Paralysis with muscular atrophy of a limb & $5 / 8$ \\
Convulsions and/or phychomotor retardation & $4 / 8$ \\
Chorioretinitis & $3 / 8$ \\
Cataracts and/or other eye defects & $2 / 8$ \\
Cortical atrophy & $3 / 8$ \\
Death & $5 / 8$ \\
\hline
\end{tabular}

Table VI Summary of clinical details in eight cases of congenital varicella

\section{Variola-vaccinia Infections}

Fetal infection with variola-vaccinia virus follows the same pattern as observed with $\mathrm{HSV}$ and V-Z virus infections. The fetal mortality rate is increased after maternal smallpox (Lynch, 1932) but the incidence is not known with any accuracy as records from countries where the disease is endemic are not available. Alastrim, or variola minor, can also cause fetal death. Two cases have been reported in detail by Garcia (1963) of macerated fetuses following alastrim at the fourth and fifth month of pregnancy in which diffuse necrotic lesions were found in the placentae and fetal viscera.

Smallpox contracted close to term can cause neonatal infection very similar to that observed in maternal varicella. Marsden and Greenfield (1934) observed 33 women who contracted smallpox during the latter stages of pregnancy. This was almost certainly due to alastrim, or variola minor, as there were only a few deaths out of 13000 patients admitted to the smallpox hospitals in London at the time (1929-1934). The 33 pregnant women gave birth to 36 infants (three twin pregnancies); of these 22 developed variola and 14 escaped. Those infants who developed infection were born during the prodromal illness of the mother or within seven days of onset of maternal rash. The infants who escaped infection were either born before the mother's illness or at least a week afterwards.

Vaccinia virus can also cause fetal infection. Approximately 20 cases have been recorded in the literature (Levine et al, 1974), nearly all of which followed primary vaccination in pregnancy or revaccination after a long interval. Only three of the liveborn infants survived and one of the features of these was the presence of large scars on the infant's skin (Harley and Gillespie, 1972). This was also a feature of a case seen by Bray (1975) following primary vaccination at the 24th week of pregnancy. The fatal cases have usually been associated with macerated fetuses and diffuse necrotic lesions on the skin and in the viscera (MacDonald and MacArthur, 1953; Tucker and Sibson, 1962).

Although the risk of fetal damage is small, vaccination is contraindicated in pregnancy unless there has been a definite contact with a known case of smallpox. Vaccination against smallpox should normally be carried out as an elective procedure.

\section{Perinatal Hepatitis B}

The recent development of sensitive methods for the detection of hepatitis B antigens and antibody has enabled investigators to study the effect of maternal hepatitis $B$ infection on the fetus and newborn 
(Zuckerman, 1975). Studies by Schweitzer et al (1973a) have identified two main types of effect. Thirteen babies born of 27 mothers who had developed overt disease acquired antigenaemia without clinical illness which persisted for prolonged periods. There was also prolonged elevation of the transaminase levels, and liver biopsies in these infants revealed unresolved hepatitis. In contrast only one infant born of an asymptomatic carrier-mother became antigen positive. Transmission of hepatitis B occurs more frequently when infection occurs in the third trimester or in the immediate postpartum period $(76 \%)$ and in only $10 \%$ where hepatitis occurred during the first six months of pregnancy (Schweitzer et al, 1973b). Acute hepatitis developed in two infants but the antigenaemia was only transient.

\section{Poliomyelitis}

Poliomyelitis in the newborn following maternal poliomyelitis in late pregnancy was a very rare occurrence before immunization against poliomyelitis was introduced. It is now a matter of academic interest. Baskin et al (1950) and Johns (1948) reported three cases of severe paralysis developing with the first seven days of life; two of the three infants died and the third was severely paralyzed. Other cases have been reviewed by Pugh and Dudgeon (1954) and by Katz (1975).

\section{Other Virus Infections}

The evidence that other virus infections can cause fetal infection or fetal damage is unconvincing (see review by Dudgeon, 1976) but the possibility that subclinical infection can cause damage must not be overlooked. Reports that maternal influenza can lead to defects of the central nervous system have been repeatedly made in the past 20 years, but if there is a cause-and-effect relationship it only occurs spasmodically. Godber (1972) has suggested that the increase in the neonatal mortality rate in the UK in 1950-51 and in 1969-70 may have been related to an influenza epidemic which occurred a few months previously. The matter is being further studied.

Mumps has been incriminated as a cause of primary endocardial fibroelastosis (St Geme et al, 1966) but with no convincing corroborative evidence (Katz, 1975).

The enteroviruses other than poliovirus have also been studied in some detail as a cause of fetal infection, but although they may effect the newborn and cause severe disease, there is no clear evidence of fetal infection.

A review of the effect of other virus infections on the fetus and newborn has recently been made by Katz (1975).

\section{Summary}

Although rubella is the only virus which can be regarded in the strict sense of the term a teratogen, there is no convincing evidence that other viruses can cause fetal damage of varying severity. The risk to the fetus appears to depend on the nature of the infectious agent, the maternal immune status and the gestational age when infection takes place. The possibility that subclinical maternal infections may cause damage must not be overlooked. As some of the viruses referred to can cause damage after the period of organogenesis, the use of the term 'teratogenic effect' in relation to viral infections is considered to be inappropriate.

I am grateful to the Editor of the British Medical Bulletin for permission to publish tables III and IV from volume 32 of the British Medical Bulletin on human malformations (1976) and also to my secretary, Miss Sandra Baxter, for help in the preparation of this paper.

\section{References}

Baskin, J. L., Soule, E. H., and Mills, S. D. (1950). Poliomyelitis of the newborn. Amer. J. Dis. Child., 80, 10-21.

Boué, A., and Loffredo, V. (1970). Avortement causé par le virus de l'herpès type- 2 isolement du virus à partir de cultures de tissus zygotiques. Presse méd., 78, 103-106.

Bray, P. T. (1975). Personal communication.

Catalano, L. W., Jr., and Sever, J. L. (1971). The role of viruses as causes of congenital defects. Ann. Rev. Microbiol., 25, 255-282.

Cooper, L. Z. (1968). Rubella: a preventable cause of birth defects. Birth Defects, 4 (7), 23-25

Cooper, L. Z. (1975). In Infections of the Fetus and the Newborn Infant, edited by S. Krugman and A. A. Gershon, pp. 1-22. Liss, New York.

Dudgeon, J. A. (1969). Congenital rubella: pathogenesis and immunology. Amer. J. Dis. Child., 118, 35-44.

Dudgeon, J. A. (1973). Future developments in prophylaxis. In Intrauterine Infections (Ciba Foundation Symposium, New Series, 10), edited by K. Elliott and J. Knight, pp. 179-198. Elsevier, Excerpta Medica, North Holland, Amsterdam.

Dudgeon, J. A. (1976). Infective causes of human malformations. Brit. med. Bull., 32, 77-83.

Embil, J. A., Ozere, R. L., and Haldane, E. V. (1970). Congenital cytomegalovirus infection in two siblings from consecutive pregnancies. J. Pediat., 77, 417-421.

Garcia, A. G. P. (1963). Fetal infection in chickenpox and alastrim, with histopathologic study of the placenta. Pediatrics, 32, 895-901.

Gershon, A. A. (1975). In Infections of the Fetus and the Newborn Infant, edited by S. Krugman and A. A. Gershon, pp. 79-95. Liss, New York.

Godber, G. E. (1972). Abortion deaths. (Letter). Brit. med. $J ., 4,424$.

Gregg, N. M. (1941). Congenital cataract following German 
measles in the mother. Trans. ophthal. Soc. Aust., 3, 35-46. Hanshaw, J. B. (1975). Personal communication.

Hanshaw, J. B., Schultz, F. W., Melish, M. M., and Dudgeon, J. A. (1973). Congenital cytomegalovirus infection. In Intrauterine Infections (Ciba Foundation Symposium, New Series, 10), edited by K. Elliott and J. Knight, pp. 23-43. Elsevier, Excerpta Medica, North Holland, Amsterdam.

Harley, J. D., and Gillespie, A. M. (1972). A complicated case of congenital vaccinia. Pediatrics, 50, 150-153.

Hayes, K., and Gibas, H. (1971). Placental cytomegalovirus infection without fetal involvement following primary infection in pregnancy. J. Pediat., 79, 401-405.

Johns, A. W. (1948). Multiple cases of acute poliomyelitis. Med. Offr, 80, 230-231.

Katz, S. (1975). Other viruses associated with infection of the fetus and newborn infant. In Infections of the Fetus and the Newborn Infant, edited by S. Krugman and A. A. Gershon, pp. 55-62. Liss, New York.

Krech, U., Jung, M., and Jung, F. (1971a). Cytomegalovirus Infections of Man. Karger, Basle.

Krech, U., Konjajev, Z., and Jung, M. (1971b). Congenital cytomegalovirus infection in siblings from consecutive pregnancies. Helv. paediat. Acta, 26, 355-362.

Kriel, R. L., Gates, G. A., Wulff, H., Powell, N., Poland, J. D., and Chin, T. D. Y. (1970). Cytomegalovirus isolations associated with pregnancy wastage. Amer.J. Obstet. Gynec., 106, 885-892.

Laforet, E. G., and Lynch, C. L., Jr. (1947). Multiple congenital defects following maternal varicella. New Engl. J. Med., 236, 534-537.

Levine, M. M., Edsall, G., and Bruce-Chwatt, L. J. (1974). Live-virus vaccines in pregnancy: risks and recommendations. Lancet, 2, 34-38.

Lynch, F. W. (1932). Dermatologic conditions of the fetus. Arch. Derm. Syph., 26, 997-1019.

MacDonald, A. M., and MacArthur, P. (1953). Foetal vaccinia. Arch. Dis. Childh., 28, 311-315.

Manson, M. M., Logan, W. P. D., and Loy, R. M. (1960). Rubella and other virus infections during pregnancy. Rep. on publ. hlth. med. subj. HMSO, London (no. 101).

Marsden, J. P., and Greenfield, C. R. M. (1934). Inherited smallpox. Arch. Dis. Childh., 9, 309-314.

Marshall, W. C. (1972). Unpublished observations.

Meyer, H. M., Jr., Parkman, P. D., and Panos, T. C. (1966). Attenuated rubella virus. 2. Production of an experimental live-virus vaccine and clinical trial. New Engl.J. Med., 275, 575-580.

Monif, G. R. G., Egan, E. A., Held, B., and Eitzman, D. V. (1972). The correlation of maternal cytomegalovirus infection during various stages in gestation with neonatal involvement. J. Pediat., 80, 17-20.

Montgomery, J. R., Flanders, R. W., and Yow, M. D. (1973). Congenital anomalies and herpesvirus infection. Amer. $J$. Dis. Child., 126, 364-366.

Montgomery, R., Youngblood, L., and Medearis, D. N., Jr., (1972). Recovery of cytomegalovirus from the cervix in pregnancy. Pediatrics, 49, 524-531.

Nahmias, A. J., Josey, W. E., Naib, Z. M., Freeman, M. G., Fernandez, R. J., and Wheeler, J. H. (1971). Perinatal risk associated with maternal genital herpes simplex virus infection. Amer. J. Obstet. Gynec., 110, 825-837.

Nahmias, A. J., Visintine, A. M., Reiman, C. B., Del Buona, I., Shore, S. L., and Starr, S. E. (1975). Herpes simplex virus infection of the fetus and newborn. In Infections of the Fetus and the Newborn Infant, edited by S. Krugman and A. A. Gershon, pp. 63-78. Liss, New York

Pugh, R. C. B., and Dudgeon, J. A. (1954). Fatal neonatal poliomyelitis. Arch. Dis. Childh., 29, 381-384.

St Geme, J. W., Jr., Noren, G. R., and Adams, P., Jr. (1966). Proposed embryopathic relation between mumps virus and primary endocardial fibroelastosis. New Engl. J. Med., 275, 339-347.

Schaffer, A. J. (1965). Diseases of the Newborn, 2nd ed., p. 733. Saunders, Philadelphia.

Schweitzer, I. L., Dunn, A. E. G., Peters, R. L., and Spears, R. L. (1973b). Viral hepatitis B in neonates and infants. Amer. J. Med., 55, 762-771.

Schweitzer, I. L., Mosley, J. W., Ashcavai, M., Edwards, V. M., and Overby, L. B. (1973a). Factors influencing neonatal infection by hepatitis B virus. Gastroenterology, 65, 277-283.

Sever, J., and White, L. R. (1968). Intrauterine viral infections. Ann. Rev. Med., 19, 471-486.

Siegel, M., Fuerst, H. T., and Peress, N. S. (1966). Comparative fetal mortality in maternal virus diseases. New Engl. J. Med., 274, 768-771.

South, M. A., Tompkins, W. A. F., Morris, C. R., and Rawls, W. E. (1969). Congenital malformation of the central nervous system associated with genital type (type 2) herpesvirus. J. Pediat., 75, 13-18.

Stagno, S., Reynolds, D. W., Lakeman, A., Charamella, L. J., and Alford, C. A. (1973). Congenital cytomegalovirus infection: consecutive occurrence due to viruses with similar antigenic compositions. Pediatrics, 52, 788-794.

Stagno, S., Reynolds, D., Tsiantos, A., Fucillo, D. A., Smith, R., Tiller, M., and Alford, C. A., Jr. (1975). Cervical cytomegalovirus excretion in pregnant and non-pregnant women: suppression in early gestation. J. infect. Dis., 131, 522-527.

Stern, H. (1975). Cytomegalovirus infection. Brit. J. clin. Pract., 29, 245-250.

Stern, H., and Tucker, S. M. (1973). Prospective study of cytomegaloviris infection in pregnancy. Brit. med. J., 2, 268-270.

Swan, C., Tostevin, A. L., Moore, B., Mayo, H., and Black, G. H. B. (1943). Congenital defects in infants following infectious diseases during pregnancy. Med.J. Aust., 2, 201.

Townsend, J. T., Baringer, J. R., Wolinsky, J. S., Malamud, N., Mednick, J. P., Panitch, H. S., Scott, R. A. T., Oshiro, L. S., and Cremer, N. E. (1975). Progressive rubella panencephalitis. New Engl. J. Med., 292, 990-993.

Tucker, S. M., and Sibson, D. E. (1962). Fetal complication of vaccination in pregnancy. Brit. med. J., 2, 237-238.

Weinstein, L., and Chang, Te Wen (1975). Prevention of rubella. Pediatrics, 55, 5-6.

Zuckerman, A. J. (1975). Perinatal hepatitis B. In Infections of the Fetus and the Newborn Infant, edited by S. Krugman and A. A. Gershon, pp. 97-113. Liss, New York. 